\title{
Forecast Competency Migration by a Methodology of Competency Analytics
}

\author{
Gang Zhao1, Debbie Carlton' \\ ${ }^{1}$ Intelartes, Brussels, Belgium \\ ${ }^{2}$ Dynamic Knowledge, London, UK \\ Email: Gang.Zhao@intelartes.com
}

Received August 2015

\begin{abstract}
Competency migration is an evolution from one competence profile to another. A basic task in forecasting competency migration is comparing competency data. It is both methodological and technological challenge to make competency data comparable syntactically and semantically, since they vary in purpose, origin, assumption and format. The paper describes a knowledgebased data processing approach to competency forecasting. It combines knowledge and data engineering methodologies and takes advantage of knowledge technologies, with the aim at objective, comprehensive, consistent, traceable and scalable analysis. The competency data are collected from Gas, Power, Waste and Water industries and analyzed for skill foresights into 2030 in a research programme at Energy \& Utility Skills Group, UK.
\end{abstract}

\section{Keywords}

Competency, Competency Framework, Gap Analysis, Knowledge Base, Competence Semantics, Competency Analytics, Career Migration, Workforce Planning

\section{Introduction}

This study is part of the research Skills Foresight: Making the Transition at the Energy \& Utility Skills Group (http://www.euskills.co.uk), intending to anticipate skill challenges in the Gas, Power, Waste and Water sectors in UK on the horizon of 2030. Based on the foresight research of key drivers and trends in these sectors [1], it studies the evolution of competency requirements from current jobs into future ones to support decisions in workforce planning and upskilling in organizational or sectorial contexts. Similar studies are occupation forecasts [2]-[5] and need analysis of competency [6]. The former presents a projection of labour markets in terms of predefined occupations on a given time horizon. The latter looks beyond job categories into the details of their skill dimensions. It collects or speculates about the competency data of given subjects such as an individual, team, organization, project, training or role at work (see [6] for a systematic methodology of defining the future competency data of a role at work).

The competency migration is about how subjects change from one set of their competency data to another. Forecasting competency migration defines and analyses competency data of different timestamps. The competency data in this context are typically created from multiple sources, in divergent perspectives and for different 
purposes. Their representation also varies from free text, questionnaire, vocabulary-controlled, keyword-based to checklists of predefined parameters from psychometrics [7] or information model [8] or competence frameworks [9]. Competency comparison is prone to subjectivity and arbitrariness, if the issue of data comparability is dealt with informally or implicitly. It is, therefore, both a technical and methodical challenge to transform competency data into terms comparable semantically as well as syntactically. Our study of methodology is focused on how to transform and compare competency data. We take a knowledge-based approach [10] to competency analysis. This approach seeks to interpret, transform and compare competency data with respect to the UK National Occupational Standards (NOS) [11]. NOS are selected as terms of reference for comparability, because of its functional approach to competence specification, in-depth and comprehensive coverage, wide consensus of employment experts and methodical compilation [12].

This approach of competency analytics is described in Section An approach of knowledge-based competency analytics and illustrated with empirical findings in Sections Competency knowledge, Competency data and Competency analysis.

\section{An Approach of Knowledge-Based Competency Analytics}

\subsection{Concepts}

Competence is a concept used in various contexts and applications, hence different viewpoints or emphasis in conceptualization and presentation. As Elleström [13] puts it, "there is such confusion and debate about the concept of competence that it is impossible to identify or impute a coherent theory or to arrive at a definition capable of accommodating and reconciling all the different ways the term is used". In our current context, however, competence refers to a capability to perform a professional duty with required ability, knowledge and behaviour. Duty is the purpose or context of professional activity, knowledge and behaviour. Ability is a capacity to conduct an activity or undertake a task for a professional duty. Knowledge is cognitive awareness of knowwhat, know-why and know-how. Behaviour is the personal traits, such as attitudes and manners, in the professional context. No conceptual distinction of potential and actual [14] is made between competence and competency. The latter is treated as a collective noun of the former.

A competency description is a free text description of competences. It is unstructured competency data found in job advertisement and descriptions. A competency specification is also textual description, but it is structured along specific conceptual dimensions such as skills, knowledge and behaviour. It is often put in restricted linguistic style with controlled syntax and vocabulary. Competency frameworks are examples of such semi-structured competency specification. A competency profile is a list of symbols representing competences and their inter-relationship for automatic data processing.

Competency analytics computes the set relationship between competency profiles. Given competency profiles, $\mathrm{A}$ and $\mathrm{B}$, the competency adequacy of $\mathrm{A}$ for $\mathrm{B}$ is their intersection, $\mathrm{i}$, where $\mathrm{i}=\mathrm{A} \cap \mathrm{B}$; the competency lack in $\mathrm{A}$ for $\mathrm{B}$ is the difference of $\mathrm{B}$ and $\mathrm{A}$, $\mathrm{g}$, where $\mathrm{g}=\mathrm{B} \backslash \mathrm{A}$; the competency redundancy of $\mathrm{A}$ for $\mathrm{B}$ is the difference of $\mathrm{A}$ and $\mathrm{B}$, $\mathrm{d}$, where $\mathrm{d}=\mathrm{A} \backslash \mathrm{B}$. The redundancy is a cost of a career move or indicator of "over-qualification": abilities, skills and knowledge will be disused, possibly depreciate in time. The competency comparison is scored between 0 and 1 , where 0 is negative and 1 is positive.

A role refers to a set of duties to perform at work. They are the subject of competency description, specification and profile in the current study. Future roles are roles predicted to come up in the future. Feeder roles, which exist in today's professional activities, are closer akin to future roles and thus are more immediate point to evolve or migrate from.

\subsection{Principles}

We have identified seven principles which competency analytics ideally adheres to. They are factuality in information collection, objectivity in analysis and conclusion, comprehensiveness in details and coverage, consensus in data interpretation and assumption, scalability in the scope of analysis, traceability towards intermediate and final results, consistency regardless of who, what, when and where the analysis is made. Factuality, objectivity, comprehensiveness and consensus are requirements on competency data and knowledge in the analysis. Consistency, scalability and traceability are guidelines for developing and evaluating the data and knowledge processing, such as data transformation and comparison in the analysis. 
In consideration of these requirements, we have adopted three strategies in our approach to forecasting competency migration: data formalization, use of a knowledge base and automation in analysis and presentation. An unstructured-to-structured transformation of competency data is implemented to restructure data conceptually and formally without reducing their factuality and comprehensiveness. It is standard-based in the light of competency frameworks to maximize its objectivity, comprehensiveness, consensus and traceability. The automatic comparison of resultant competence profiles guarantees the consistency, traceability and scalability of analysis. Its reference to competence frameworks maintains comprehensive and consensus-based business logic.

\subsection{Processes}

Our approach of competency analytics implements three processes: knowledge engineering, data engineering, knowledge-based data processing (Figure 1).

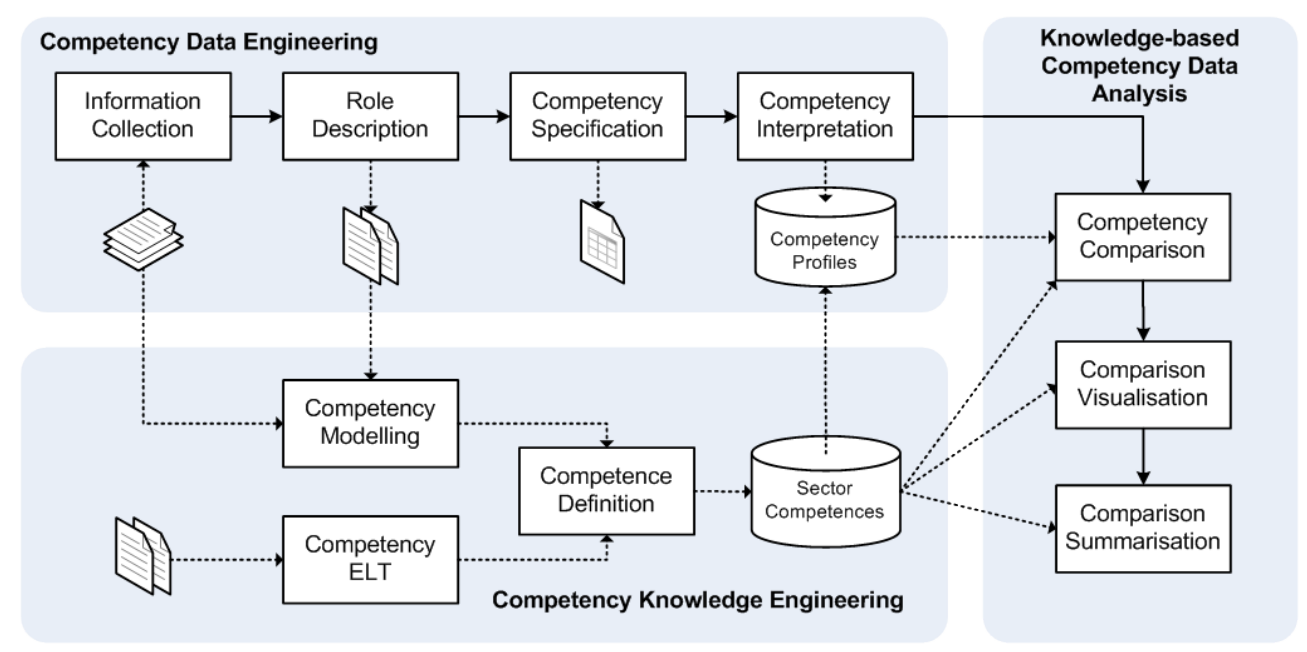

Figure 1. Processes of knowledge-based data engineering and processing.

Competency knowledge engineering develops a Sector Competence Knowledge Base (SCKB) from NOS. Similar to other competency frameworks, NOS is intended for human readership. It is not a formal model, readily available for automatic competency processing. This is a major technological challenge to the adoption of competency frameworks in machine-assisted competency management. We make use of knowledge base and semantics technology [15] to make its contents deployable for automatic processing. The machine knowledge base of competences adds intelligence to competency processing, as well as improves the consistency, objectivity, traceability, comprehensiveness and scalability of competency analytics. In addition to the standard competence framework with NOS, a competency model is built for the specific purpose and integrated in SCKB, which serves to highlight specific competences found in the context of the current study.

Competency data engineering is a two-step unstructured-to-structured data transformation to make data comparable for traceable, consistent and scalable analysis. The first step is to paraphrase competency descriptions into competency specifications in view of our definition of competence and assumptions in NOS. The second step is to interpret competency specifications into competency profiles manually or automatically according to the NOS competence framework and purpose-built competence model.

Knowledge-based competency data analysis compares competency profiles with reference to SCKB to quantify and visualize the competency adequacy, lack and redundancy in a move of competency migration.

\section{Competency Data}

Four future roles are defined for the sectors of Gas, Power, Waste and Water respectively. Three feeder roles for each future role are identified from job boards and validated through extensive interviews and stakeholder workshops [16]. Sixteen role descriptions are edited from collected job information and paraphrased into competence specifications, written in simple declarative statements of action, state and attribute, structured under 5 headings: 
- Duty

- Ability

Responsibility or function of the role

- Knowledge

Capability to conduct activities to fulfill the duty or role

- Behaviour

Know-what, know-why and know-how required to fulfill the duty or role

- Qualification Certification or education required for the duty or role

Sixteen competency profiles (Figure 2) are interpreted from resultant competence specifications according to NOS.

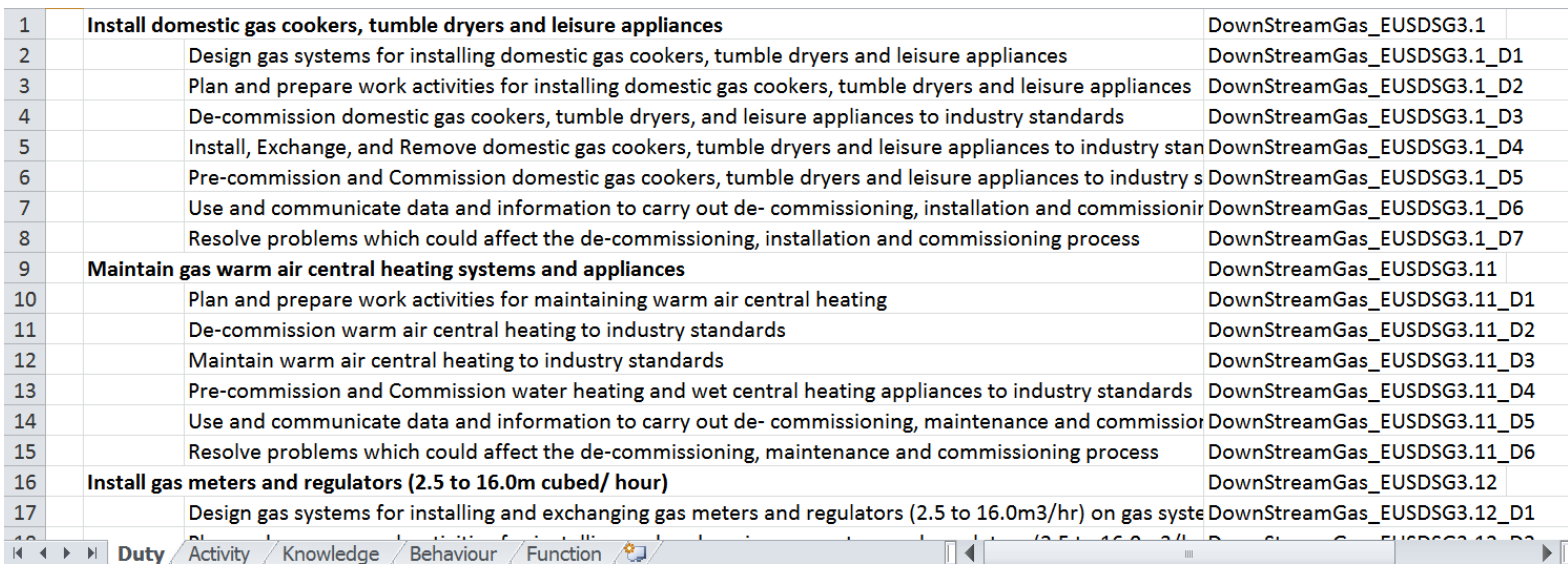

Figure 2. Excerpt of competency profile data sheet.

Competency interpretation thus refers to a competency descriptive framework instead of a reductionist model of competency categorization or taxonomy. This non-reductionist approach is taken in order to maintain the factuality, objectivity and comprehensiveness of competency profiles. Table 1 shows the numbers of competences of their competence profiles of the future and associated feeder roles.

Table 1. Roles and numbers of associated competences.

\begin{tabular}{|c|c|c|c|c|c|c|c|}
\hline Role & Abbr. & Sector & Type & Duty & Ability & Knowledge & Behaviour \\
\hline Gas Network Planner & $G N P$ & Gas & Future & 139 & 910 & 1497 & 65 \\
\hline Energy Demand Manager & EDM & Gas & Feeder & 19 & 207 & 356 & 41 \\
\hline Network Maintenance Planning and Performance Manager & NMPPM & Gas & Feeder & 68 & 583 & 1023 & 90 \\
\hline Network Planner & NP & Gas & Feeder & 34 & 319 & 695 & 44 \\
\hline Commercial Director of Resource Operations & CDRO & Waste & Future & 153 & 1158 & 1077 & 84 \\
\hline Carbon Manager & $\mathrm{CM}$ & Waste & Feeder & 51 & 430 & 629 & 39 \\
\hline Head of Sustainability & HS & Waste & Feeder & 48 & 551 & 643 & 56 \\
\hline Senior Resource Efficiency \& Waste Consultant & SREWC & Waste & Feeder & 60 & 484 & 1311 & 49 \\
\hline Power Balance Technician & PBT & Power & Future & 59 & 272 & 165 & 26 \\
\hline Electrical Control Room Engineer & ECRE & Power & Feeder & 29 & 148 & 427 & 16 \\
\hline Power System Analysis Engineer & PSAE & Power & Feeder & 19 & 64 & 60 & 12 \\
\hline Transmission Control Engineer & TCE & Power & Feeder & 72 & 489 & 360 & 32 \\
\hline Water Treatment Engineer & WTE & Water & Future & 90 & 840 & 867 & 47 \\
\hline Network Engineer & NE & Water & Feeder & 134 & 1553 & 1170 & 63 \\
\hline Process Engineer & $\mathrm{PE}$ & Water & Feeder & 93 & 833 & 971 & 41 \\
\hline \multirow[t]{2}{*}{ Water Treatment Engineer } & WTE & Water & Feeder & 103 & 1050 & 1873 & 40 \\
\hline & & & Average & 73 & 618 & 820 & 47 \\
\hline
\end{tabular}


The statistics reveals that competency interpretation and comparison are beyond what human cognition can handle consistently at this level of knowledge details without technical aids. This has not yet taken into account of the complexity due to synonymous, logical or co-occurring relationship among the competences. It is thus a methodological challenge to maintain consistency, traceability and scalability over such comprehensive knowledge coverage and assumption and potentially large data sets.

\section{Competency Knowledge}

The competency knowledge engineering builds SCKB as terms of reference for competency interpretation and comparison. The purpose is to project the competency data of a role on the canvas of NOS for comparison. The process extracts competences from NOS documents, transforms them into competence entries and loads into SCKB. It consists of 33 sector specific competence themes such as utility management, network design and construction, utility metering, gas utilization, waste management, water treatment, and five common themes, for example, customer service, supply chain management, environmental and social governance (Table 2).

Table 2. Competence entries by theme in SCKB.

\begin{tabular}{cccccccc}
\hline Dimension & Utility & Gas & Power & Waste & Water & Common & Average \\
\hline Duty & 222 & 33 & 288 & 310 & 221 & 41 & 186 \\
Ability & 1300 & 3122 & 1333 & 2093 & 1837 & 1181 & 1811 \\
Knowledge & 1630 & 4338 & 1342 & 2051 & 2322 & 1604 & 2215 \\
Behaviour & 47 & 47 & 55 & 112 & 50 & 83 & 66 \\
Total & 3199 & 7540 & 3018 & 4566 & 4430 & 2909 & 4277 \\
\hline
\end{tabular}

It also includes a set of special competences of 75 activities, 135 knowledge (know-what and know-how), 39 behaviours, 13 qualifications and 29 experience in posts. They are modelled from the 16 role specifications, purpose-built to emphasize and complement specific aspects of the NOS sector coverage (Table 3).

Table 3. Excerption of purpose specific competences.

\begin{tabular}{|c|c|c|c|c|}
\hline Activity & Knowledge & Behaviour & Qualification & Experience \\
\hline Advise & $3 \mathrm{D}$ modeling & Action-oriented & APM practitioner & $\begin{array}{l}\text { Asset intervention } \\
\text { manager }\end{array}$ \\
\hline $\begin{array}{l}\text { Analyse cost } \\
\text { and effect }\end{array}$ & 6 Sigma & Analytical & BEng & Biologist \\
\hline Analyse data & $\begin{array}{l}\text { Bidding, tendering } \\
\text { and contracting }\end{array}$ & Articulate & BSc & Chemical engineer \\
\hline Analyse prices & biochemistry & Commerce-oriented & $\begin{array}{c}\text { Chartered quantity } \\
\text { surveyor }\end{array}$ & Chemist \\
\hline Analyse quality & Biomethane injection & Communicative & CIWM & Civil engineer \\
\hline$\ldots$ & $\cdots$ & $\ldots$ & $\ldots$ & $\ldots$ \\
\hline
\end{tabular}

Competence semantics [15] are extracted from competence entries with semantics and language technologies for competency comparison in semantic terms. It is beyond the scope of the paper and will be discussed in a technical publication to come.

\section{Competency Analysis}

The competency analysis in the current study takes two views: data comparison and analytical comparison. The Competency Comparison in the data view compares competence profiles automatically with reference to competences and their semantics in SCKB in order to identify, quantify and visualize the competency adequacy, lack and redundancy of feeder roles for future roles (Figure 3). 


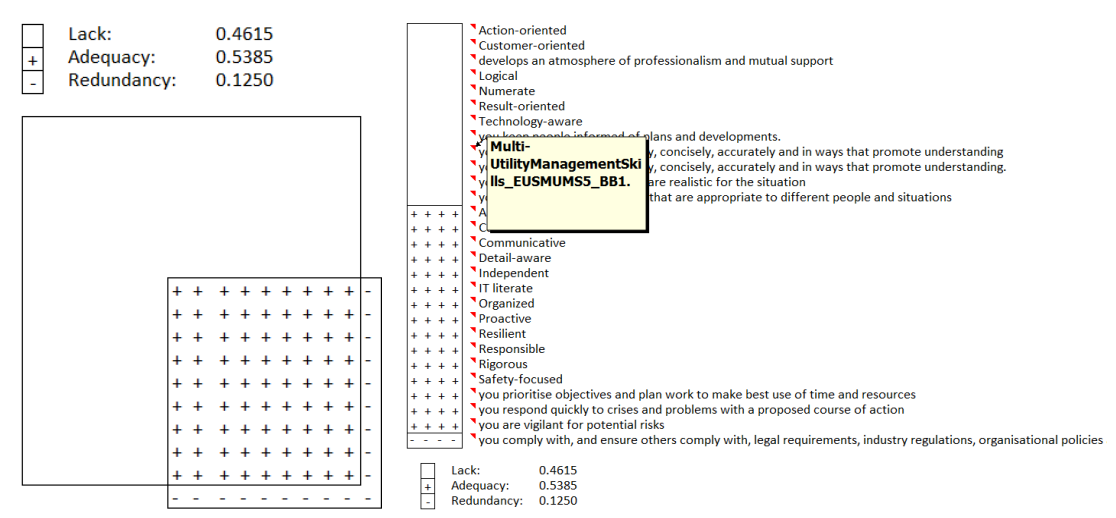

Figure 3. Views of behaviour comparison of PBT with ECRE.

Figure 4 visualizes the competency of three feeder roles compared with that of the future role, water treatment engineer on 4 competency dimensions. The current study does not consider the life cycle of competences [6], though it can be introduced to weigh the score of competency adequacy, lack and redundancy.

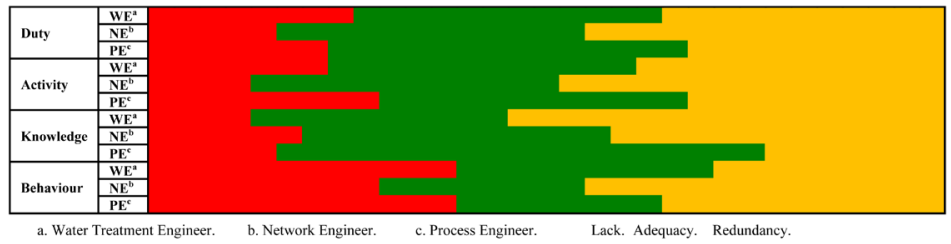

Figure 4. Dimensional view of competency of feeder roles compared with the future role of water treatment engineer.

The Analysis Summarization seeks to create an analytic analysis, summarized from data views of competency, on parameters or dimensions of different abstraction or perspectives. Table 4 presents a strategic view of competency comparison, an executive summary from the perspective of 11 functional skills. The star indicates the existence of the competence in the role. The score from 0 up to 10 indicates the extent of overall competency adequacy of the role by the dimension. It serves to reveal highlight key aspects, given specific motivations of analysis. Though it is selective and generalized, the summarization analysis is based on a comprehensive and objective data analysis of multiple dimensions and large sets of parameters of data description. The analytic views are thus grounded on comprehensiveness, factuality and consistency in description.

Table 4. Analytic overview of functional skills comparison.

\begin{tabular}{|c|c|c|c|c|c|c|c|c|c|c|c|c|c|c|c|c|}
\hline Functional Skill & GNP & EDM & NMPPM & NP & CDRO & $\mathrm{CM}$ & HS & SREWC & PBT & ECRE & PSAE & TCE & WTE & $\mathrm{NE}$ & $\mathrm{PE}$ & WTE \\
\hline $\begin{array}{l}\text { Manage data, information } \\
\text { and knowledge }\end{array}$ & * & $*$ & * & * & * & * & * & * & * & * & $*$ & * & * & $*$ & * & * \\
\hline Organize work & $*$ & & $*$ & * & $*$ & * & $*$ & $*$ & * & $*$ & & & $*$ & $*$ & & * \\
\hline Manage work relations & $*$ & * & * & $*$ & $*$ & * & $*$ & $*$ & * & $*$ & & $*$ & $*$ & $*$ & * & * \\
\hline Manage risks and hazards & $*$ & & * & & $*$ & & & & $*$ & & & * & * & $*$ & * & * \\
\hline Control quality & $*$ & & * & & $*$ & & & * & & $*$ & $*$ & $*$ & & $*$ & $*$ & \\
\hline Systems and utilities & $*$ & & & & & & & & & * & $*$ & * & * & & * & $*$ \\
\hline $\begin{array}{c}\text { Instrument } \\
\text { (use \& manage ICT etc.) }\end{array}$ & $*$ & & & & $*$ & $*$ & & * & * & & * & * & * & * & * & * \\
\hline Ensure compliance & * & * & * & * & * & * & * & & & $*$ & * & * & * & * & & $*$ \\
\hline Emergency (incl. contingency) & & & & & $*$ & & & & & & & * & $*$ & & & \\
\hline $\begin{array}{l}\text { Manage training \& } \\
\text { knowledge transfer }\end{array}$ & & & & & $*$ & & & & & & & & & & & \\
\hline \multirow[t]{2}{*}{$\begin{array}{l}\text { Develop sustainable } \\
\text { business practice }\end{array}$} & & & & & $*$ & & * & $*$ & & & & & & & & \\
\hline & 10 & 4 & 6 & 5 & 10 & 5 & 5 & 6 & 10 & 6 & 4 & 8 & 10 & 8 & 6 & 9 \\
\hline
\end{tabular}




\section{Conclusions}

The paper presents a methodology of competency analytics for a knowledge-based data processing approach to forecasting competency migration. It promotes an objective, comprehensive, consistent, traceable and scalable analysis of competency data. It supports both the data and strategic views of competency migration for planning workforce, career moves and upskilling pathways [16]. The use of SCKB introduces methods and technologies of knowledge engineering and management to take advantage of extensive development of competency frameworks as well as adding machine intelligence in processing human resource data. This knowledge based approach promises an effective way to adopt, implement and institutionalize the competency standards and policies. The approach with the methodology constitutes a central component to competency assurance in human resource management and development.

The manual competence interpretation is highly skilled work requiring good knowledge of human resource management and expert understanding of NOS and competency data in the sector. The work is demanding intellectually and error-prone due to monotony in routine, superficial similarity in the data, the large population of data and scope of knowledge involved. We have explored the automatic interpretation by the case-based reasoning approach [17] to resolve this issue of scalability. The competence profile is inferred from the competency specification analogically by a case library of roles and their competency profiles. A detailed description will be the topic of a technical paper on competency analytics.

\section{Acknowledgements}

Skills Foresight: Making the Transition by Energy \& Utility Skills Group was funded by UK Commission for Employment and Skills (UKCES) under the auspices of the Employer Investment Fund. The authors wish to thank Nathan Baker, former Strategy \& Development Director and Grace Storey, Strategy Manager, of Energy \& Utility Skills Group for their advice and support for the completed study.

\section{References}

[1] EU Skills Group (2014) Skills Foresight: Making the Transition, Energy and Utility Skills.

[2] LMIP (2015) Employment Projections. Australian Government Department of Employment.

[3] FOREM (2013) Métiers d'avenir-États des lieux sectoriels et propositions de futurs. Recueil prospectif.

[4] MBIE (2015) Occupation Outlook 2015. New Zealand Ministry of Business, Innovation and Employment.

[5] BLS (2015) Occupational Outlook Handbook. United States Department of Labor. http://www.bls.gov/ooh/

[6] Robinson, M., Sparrow, P., Clegg, C. and Birdi, K. (2007) Forecasting Future Competency Requirements: A ThreePhase Methodology. Personnel Review, 36, 65-90. http://dx.doi.org/10.1108/00483480710716722

[7] SHL (2015) SHL Talent Measurement. http://ceb.shl.com/us

[8] Elia, G. and Margherita, A. (2015) Next-Generation Human Resource Management: A System for Measuring and Visualising Professional Competencies. International Journal of Human Resources Development and Management, 15, 1-15. http://dx.doi.org/10.1504/IJHRDM.2015.069975

[9] CIEEM (2015) CIEEM Competency Framework. Chartered Institute of Ecology and Environmental Management. http://www.cieem.net/competency-framework

[10] Stefik, M. (1995) Introduction to Knowledge Systems. Morgan Kaufmann Publishers, San Francisco.

[11] UKCES (2015) National Occupational Standards. http://www.ukstandards.co.uk/Pages/index.aspx

[12] NOS (2011) Guide to Developing NOS, Version 2, 24-40.

[13] Elleström, P.-E. (1997) The Many Meanings of Occupational Competence and Qualification. Journal of European Industrial Training, 21, 266-273. http://dx.doi.org/10.1108/03090599710171567

[14] Schroeter, K. (2008) Competence Literature Review. CCI.

[15] Zhao, G. (2012) Competence Semantics: Engineering and Application. Int. J. Knowledge and Learning, 8, $112-132$. http://dx.doi.org/10.1504/IJKL.2012.047553

[16] EUS (2014) Making the Transition, Appendix 2: Skill Foresights. EU Skills Group.

[17] Aamodt, A. and Plaza, E. (1994) Case-Based Reasoning: Foundational Issues, Methodological Variations and System Approaches. AI Communications, 7, 39-59. 